\title{
"DORES, DILEMAS E DESCOBERTAS": DESAFIOS DE PROFESSORES INICIANTES NA CARREIRA DO MAGISTÉRIO
}

\author{
Marcela Marques Umbellino ${ }^{1}$ \\ Klinger Teodoro Ciríaco ${ }^{2}$
}

Resumo: O artigo aborda questões sobre os desafios presentes no trabalho pedagógico de professores iniciantes que atuam em diferentes níveis de ensino e tem como objetivo geral apresentar dados de uma pesquisa qualitativa em que se buscou investigar como são os primeiros anos da carreira. Para tal, a coleta de dados ocorreu a partir de informações de narrativas escritas e orais de quatro professores, sendo eles da Educação Infantil, Ensino Fundamental, Ensino Médio e Ensino Superior atuantes no município de Naviraí/MS em que procuramos identificar algumas dificuldades presentes na iniciação à docência. Os dados apontam que as primeiras vivências no espaço de atuação pedagógica são marcadas por aprendizagens intensas e conflitos pessoais, como também que o apoio institucional se apresenta como fundamental para o desenvolvimento profissional do professor novato.

Palavras-chave: Inserção na carreira. Professores iniciantes. Dilemas e dificuldades.

\section{“PAINS, DILEMMAS AND FINDINGS": TEACHERS BEGINNERS CHALLENGES IN TEACHING CAREER}

\begin{abstract}
The article addresses questions about the challenges in the educational work of beginning teachers who work at different levels of education and has the general objective to present data from a qualitative research that aimed to investigate how the early years of his career are. To this end, data was collected from information written and oral narratives of four teachers, and they from kindergarten, elementary school, high school and higher education operating in the city of Navirai/MS in which we try to identify some difficulties present in initiation to teaching. The data show that the first experiences in the pedagogical performance space are marked by intense learning and personal conflicts, as well as the institutional support presents as critical to the professional development of novice teacher.
\end{abstract}

Key words: Insertion career. Beginning teachers. Dilemmas and difficulties.

\footnotetext{
${ }^{1}$ Professora de Educação Infantil da Rede Municipal de Educação de Naviraí/MS; Licenciada em Pedagogia pela UFMS, Câmpus de Naviraí.

${ }^{2}$ Professor Assistente e Coordenador do Curso de Pedagogia da Universidade Federal de Mato Grosso do Sul, UFMS/Câmpus de Naviraí; Doutorando em Educação pela UNESP, Presidente Prudente/SP.
} 


\section{INTRODUÇÃO}

Todo início de carreira é difícil e com a docência não é diferente. Na maioria das vezes não sabemos o que nos espera no caminho que iremos percorrer na árdua tarefa docente, pois ser professor é deparar-se a cada dia com novas situações e experiências, independentemente do tempo de docência, sempre iremos encontrar situações novas.

A escolha da temática de pesquisa que aqui será relatada teve influência da participação ativa em ações ligadas ao Grupo de Estudos e Pesquisas sobre Início da Docência e Ensino de Matemática (GEPIDEM/UFMS/CNPq). A experiência no grupo despertou a vontade de saber como o docente, no início de sua carreira, lida com as dificuldades e quais medidas de superação são utilizadas por ele para sobreviver na profissão. Nesse artigo, propomos discutir os dados de uma pesquisa desenvolvida no referido do grupo de estudos e que está vinculada à Universidade Federal de Mato Grosso do Sul, UFMS/Câmpus de Naviraí.

Acreditamos que a pesquisa com professores iniciantes é um campo que deveria ser mais explorado, pois atualmente ocorre um avanço crescente na necessidade de formação de novos professores para atender a demanda advinda da democratização do acesso à educação.

Muitos desafios serão encontrados pelos professores quando ingressarem no mercado de trabalho e, independentemente do nível de ensino, eles terão de lidar com as dificuldades e situações difíceis para se desenvolverem profissionalmente no campo da atuação docente. Desse modo, a presente pesquisa procura compreender quais são os desafios encontrados e como esses profissionais fazem para superá-los a cada dia.

O trabalho docente é um processo complexo de formação que ocorre com base na mediação e da interação entre professor e alunos. Ao iniciar a carreira vivenciam situações novas e a cada dia vão construindo novas experiências profissionais com as práticas realizadas em seu cotidiano. O método adotado nesse estudo foi o hipotéticodedutivo, implementado a partir da coleta de dados e o diálogo com a literatura sobre a temática do professor em início de carreira na tentativa de conhecer um pouco mais detalhadamente as problemáticas que emergem da atuação de professores novatos na Educação Infantil, Ensino Fundamental, Ensino Médio e Ensino Superior.

Por meio dos estudos e análises das narrativas dos professores, obtidas em dados de diários reflexivos e das entrevistas, podemos contribuir com os estudos da área, buscando apresentar diferentes visões do campo de atuação dos docentes, demonstrando 
a importância da formação desses profissionais na perspectiva do desenvolvimento na carreira.

Nessa perspectiva, a exploração e discussão acadêmica desta problemática poderão subsidiar a crescente discussão acerca da necessidade de formação de professores bem qualificados para atender as novas demandas impostas pela realidade da escola.

\section{FORMAÇÃO DE PROFESSORES E INÍCIO DA DOCÊNCIA: PROBLEMAS E PERSPECTIVAS}

Os intensos debates em torno da formação docente, tanto de professores da Educação Infantil, Ensino Fundamental e Médio, como universitário, levam indiscriminadamente a questões fundamentais sobre a dimensão pedagógica do ensino e da educação em geral. Nunes (2001) aponta que durante sua trajetória profissional o professor constrói e reconstrói seus conhecimentos conforme a necessidade de utilização deles, suas experiências e seus percursos formativos e profissionais.

$\mathrm{Na}$ visão de Guarnieri (2005, p. 06) “[...] há indicadores que sugerem que, para ter sucesso profissional na tarefa de ensinar, é necessário ao professor conhecer, dominar e articular os vários elementos que compõem o seu trabalho". Assim, podemos reconhecer a educação como processo de aprendizagem à leitura e escrita do mundo, podemos igualmente reconhecer que as concepções dominantes na pedagogia se aproximam da racionalidade que guia a vida no mundo contemporâneo (CELESTINO, 2011).

Todo início de carreira é difícil, desta forma porque a docente seria diferente? $\mathrm{Na}$ maioria das vezes não sabemos o que nos espera no caminho que iremos percorrer na profissão na qual ingressamos, pois ser professor é se deparar a cada dia como novas situações e experiências nunca antes vividas isso ocorre independente do tempo de docência que temos.

Esta visão é corroborada com Mariano (2006, p. 18), ao afirmar que "[...] por mais que estudemos o nosso papel e nos julguemos preparados para assumi-lo, sempre iremos encontrar situações nunca antes imaginadas nem vivenciadas", demonstração inequívoca de que o docente seria fadado a ser, na prática, um eterno aprendiz.

Nesta concepção, o trabalho docente é visto como um processo educativo de instrução e de formação humana, por meio da mediação e da interação entre professor e 
alunos, a partir dos conteúdos do ensino em direção à construção de uma sociedade verdadeiramente humana, em que os sujeitos constroem sua identidade no seio de uma coletividade. Nós, professores iniciantes na carreira, iremos vivenciar situações inusitadas a cada dia "[...] Aprenderemos a construir o nosso eu profissional com a ajuda de nossos pares, da equipe de direção, dos pais de nossos alunos e de nossos alunos também" (MARIANO, 2006, p. 25).

Algumas implicações epistemológicas fundamentam nossa concepção de trabalho docente enquanto práxis transformadoras de um sujeito (professor) em interação situada com outro sujeito (aluno), onde a produção de saberes e de significados caracterizam e direcionam o processo de comunicação, o diálogo e o entendimento entre ambos na direção de uma emancipação fundada no ser social (NUNES, 2001).

Martinho (2000, p. 279) afirma que:

[...] a formação de professores é, simultaneamente, um problema político, uma vez que implica uma concepção da sociedade e um projeto de futuro, um problema social, por mobilizar dados provenientes das mais diversas ciências da educação e reflete desse modo, o seu estado de desenvolvimento, conduzindo à adoção de novos conceitos e de novas formas de encarar o pacto educativo.

A sociedade busca e precisa de educadores com visão emancipada, que possibilitem transformar as informações em conhecimento e em consciência crítica, para formar cidadãos sensíveis e que busquem um mundo mais justo, mais produtivo e saudável para todos. Toda pessoa que trabalha com educação, seja na educação infantil, Ensino Fundamental ou Ensino Superior, está ajudando a formar cidadãos que construirão a sociedade em que vivem.

Em suas análises Ciríaco e Morelatti (2013, p. 04) apontam a necessidade de se “[...] (re) pensar a formação inicial de professores tendo, como ponto de partida, o contexto de seu trabalho [...]", as experiências diversas de vida cultural, social, familiar, escolar, além de expressar os elementos curriculares, disciplinares e pedagógicos dos seus diversos atores. Considerando a realidade presente na formação docente, é possível afirmar que os professores recém-formados parecem pouco saber sobre as dificuldades do trabalho docente e, muito menos, sobre as formas de lidar com os problemas que irão enfrentar.

Para os autores Ghedin, Almeida e Leite, (2008), não se pode considerar essa formação deslocada ou distanciada da reflexão crítica acerca da realidade do professor. 
O desafio da matéria em situações reais de prática e de tomada de decisão obriga o professor a produzir soluções articulando adequada e criativamente seus saberes num contexto de interação com outros sujeitos em diferentes contextos de trabalho. O professor deve utilizar medidas específicas para que os alunos realmente compreendam o conteúdo explicado.

Nesse contexto, o docente é visto como um profissional do saber que domina determinados saberes em uma situação de ensino, transformando configurações a estes, e ao mesmo tempo, assegurando a dimensão ética de suas práxis cotidiana. Ciríaco e Morelatti (2013, p. 04) enfatizam a ideia de que,

[...] ao considerarmos a realidade presente, no contexto da formação docente, é possível afirmar que os professores egressos dos cursos de licenciatura pouco sabem sobre as atribuições do trabalho docente e, muito menos, sobre as formas de organização curricular dos conteúdos que irão ensinar.

O desafio da gestão pedagógica e da transformação pedagógica da matéria em situações reais de prática e de tomada de decisão na sala de aula e em outros espaços educativos obriga o professor a gerar ou produzir saberes quando articula adequada e criativamente seu reservatório de saberes num determinado contexto de interação com outros sujeitos, alunos, na interação com a classe ou em diferentes contextos de trabalho. Em nome deste conhecimento, o professor lança mão de outros conhecimentos para que os alunos realmente compreendam o conteúdo explicado (NONO, 2011).

É dever do Estado oferecer recursos necessários para que haja a profissionalização adequada, proporcionando que seja levado adiante, o difícil projeto da qualidade da educação para todos e a de transformação cultural e social (GATTI, BARRETTO; ANDRÉ, 2011).

\section{APRENDIZAGEM DA DOCÊNCIA: O DESAFIO DE ENSINAR O QUE NEM SEMPRE APRENDEMOS}

Quando nos referimos ao aprender a ensinar, não podemos deixar esquecido que este processo se dá através da teoria e prática, com isso a preocupação inicial era centrada nos professores em formação, pouco a pouco surgem também estudos voltados aos professores iniciantes na docência, as pesquisas vêm tendo um grande avanço no como apreender a ensinar, de que forma isso ocorre? As indagações surgidas querem 
responder como os professores geram o conhecimento e quais conhecimentos adquirem ao longo de sua formação e durante a docência? (MARCELO, 1997).

Nessa perspectiva, Carter (1990, p. 99), aponta que, “[...] o conhecimento prático dos professores, que se refere, de forma ampla, ao conhecimento que os professores possuem sobre as situações de classe e os dilemas práticos que se apresentam para levar a cabo metas educativas nessas situações [...]".

O professor enquanto sujeito hermenêutico, exerce uma função de intérprete dos processos de ensino-aprendizagem voltados para a construção de sentidos e de significados. Para Guarnieri (2005, p. 09) “[...] os problemas da prática docente, para esse modelo, podem ser resolvidos mediante o uso do conhecimento produzido pela investigação científica, que é considerado útil para orientar tal prática”. Mediador de saberes, sua prática é reflexiva e transformadora.

Nono (2011, p. 48), declara que,

Representando uma combinação entre conhecimento da matéria e conhecimento do modo de a ensinar, o conhecimento pedagógico do conteúdo é apontado como um novo tipo de conhecimento da área que é desenvolvido pelo professor, ao tentar ensinar um tópico em particular a seus alunos.

Nossa compreensão do docente, como profissional do saber, deve considerar a dimensão ética do trabalho, construindo uma reflexão sobre a função do professor e de seus conhecimentos refletidos nos alunos e nos familiares desses. Nono (2011, p.17) deixa claro em seu texto que "[...] o elemento de descoberta tem a ver com o entusiasmo do iniciante, com o orgulho de, finalmente, ter sua própria classe, seus alunos, e fazer parte de um corpo profissional".

Com base na afirmação da autora podemos considerar que a responsabilidade do professor vai além da sala de aula, seja o professor da educação infantil, do ensino fundamental e médio, ou aquele que leciona na Universidade, seja ela pública ou particular, pois, a transmissão dos pensamentos e reflexões do professor atinge não só os alunos, mas suas famílias, os amigos, os seus companheiros de trabalho.

Dentro de sua sala de aula o professor iniciante acaba por reproduzir de certa forma as experiências vividas durante sua formação enquanto aluno, ele ensina da forma que aprendeu, sendo este o ponto primordial para a compreensão de seu trabalho como docente (CIRÍACO; MORELATTI, 2013). Ser professor, é viver o seu tempo 
com sensibilidade e consciência, é preciso saber lidar com as diferenças, ter flexibilidade e ajudar o seu aluno a refletir, é ser um emancipador do saber.

O professor é um parceiro de visão e experiência na construção do conhecimento, assumindo o seu papel de promotor, orientador, mediador, motivador e gestor da aprendizagem, o professor deve ser fonte de motivação para o aluno.

Nessa direção, Tardif, Lessard e Lahaye, (1991, apud GUARNIERI, 2005, p. 10) questionam que:

[...] esse modelo tem se pautado no reconhecimento do papel do professor não como um técnico que aplica à sua prática as teorias transmitidas pelos cursos de formação, mas como um profissional que adquire e desenvolve conhecimentos a partir da prática e no confronto com as condições da profissão.

É fundamental que o professor como promotor da aprendizagem, deve facilitar o acesso aos dados e informações, e ao conhecimento acumulado pela sociedade, orientando, executando e avaliando eventos, experiências e projetos, para que ocorra a construção do conhecimento. Contudo, o professor apenas conseguira realizar esta função de facilitador por meio da junção da teoria (formação) com a prática pedagógica, porém esta relação não possibilitara identificar com clareza o processo de aprendizado de sua profissão, pois os conhecimentos teórico-acadêmicos e outros oriundos desse processo serviram como reflexão sobre a prática exercida pelo professor (GUARNIERI, 2005).

Nessa perspectiva, a formação e a formação continuada do professor é de suma importância para o sucesso de sua carreira enquanto docente, seria oportuno relembrar que:

Diante das preocupações em torno dos conhecimentos profissionais docentes, estudos sobre conhecimento pedagógico do conteúdo se configuram como uma das contribuições mais poderosas e atuais da investigação sobre formação de professores (NONO, 2011, p. 49).

Podemos considerar que o professor tem uma importância muito grande para a sociedade, é uma das profissões mais antigas e mais importantes pelo seu papel na formação do cidadão. Os pais entregam seus filhos em suas mãos e confiam no desempenho do seu trabalho, para que despertem neles o gosto pelo aprender.

Freire (1996, p. 43) aponta em seus estudos que “[...] na formação permanente dos professores, o momento fundamental é o da reflexão crítica sobre a prática. É pensando criticamente a prática de hoje que se pode melhorar a próxima prática [...]”, 
podemos afirmar que a oferta de recursos adequados é necessária para que seja levado adiante o difícil projeto da qualidade da educação para todos visando uma transformação cultural e social. Para esse problema ser resolvido é necessário o uso do conhecimento produzido pela investigação científica, para orientar a prática e a formação do docente.

Desse modo, é importante compreender que são muitos os problemas enfrentados pelos professores no início de sua carreira docente, um deles é o "choque com a realidade", com relação à ideia proposta Veenman (1984, p. 01) nos mostra que "este conceito é usado para indicar o colapso dos ideais missionários formados durante o treinamento de professor pela realidade árdua e rude da vida diária em sala de aula", vemos que nem sempre o que estudamos na teoria confere com a prática dentro das salas de aula, havendo assim uma ruptura com a realidade. Para o autor:

[...] "choque da realidade" é um termo usado de forma um pouco inapropriada, porque ele sugere apenas um choque muito curto pelo qual se tem de passar [...]. De fato, o choque da realidade envolve a assimilação de uma realidade complexa que se força incessantemente sobre o professor iniciante, todos os dias. Esta realidade deve ser dominada continuamente, especialmente o primeiro período de ensino real. (VEENMAN, 1984, p. 01).

Com relação às ideias propostas pelo autor, esta não é apenas o único desafio enfrentado pelos professores em início de carreira, existem diversos problemas que vão aparecendo no decorrer dos dias lecionados desde a dificuldade com o controle em sala de aula, dificuldade de relacionamento com os pais dos alunos, indisciplina, até mesmo a relação com os professores veteranos e com a gestão escolar. Ainda sobre essa questão, Veenman (1984, p. 27), vem ressaltar que “[...] não se pode excluir a possibilidade de que os problemas relatados tinham apenas uma relação remota com os problemas reais dos professores iniciantes e que poderiam não prejudicar em nada o seu relacionamento".

Frente a essa problemática, a pesquisa que nos propomos a realizar foi ao encontro das ideias de Veenman, uma vez que procuramos analisar cuidadosamente esses "problemas" enfrentados pelos professores, desafios esses que, independentemente do nível de ensino, sempre estão presentes no cotidiano daqueles que estão iniciando a carreira docente. 


\section{PROCEDIMENTOS METODOLÓGICOS}

O presente trabalho teve como metodologia uma abordagem qualitativa, com estudos bibliográficos os quais foram realizados com base em pesquisas que tiveram em sua essência a caracterização dos sentimentos do início da docência e retrataram algumas situações difíceis e dilemas enfrentados por professores iniciantes.

Nessa perspectiva, o objetivo geral do estudo ora apresentado refere-se à compreensão dos desafios encontrados pelos professores no início da carreira docente em diferentes níveis de ensino tendo em vista a relação com formação inicial. Para tal, nossa base teórico-metodológica fundamentou-se em autores como: Celestino (2011); Ciríaco e Morelatti (2013); Guarnieri (2005); Lima (2006); Martinho (2000); Nono (2011); Nunes (2001), entre outros autores que nos auxiliaram no diálogo com a pesquisa em relação ao professor iniciante.

Utilizamos também do método autobiográfico por meio de narrativas de quatro professores iniciantes como objetivo de tentar caracterizar sentimentos e dificuldades desses docentes que atuam em diferentes níveis de ensino, a saber: Educação Infantil, Ensino Fundamental, Ensino Médio e Ensino Superior, todos atuantes na rede pública e particular de ensino no município de Naviraí/MS.

Consideramos que por meio dessa abordagem metodológica, os professores puderam apresentar suas práticas pedagógicas em diários reflexivos que oportunizamos a eles no início do ano letivo de 2014 com o objetivo de que registrassem por escrito suas memórias diárias em sala de aula. Segundo Cunha (1997, p.03) “Ao mesmo tempo em que o sujeito organiza suas ideias para o relato - quer escrito, que oral - ele reconstrói sua experiência de forma reflexiva e, portanto, acaba fazendo uma autoanálise que lhe cria novas bases de compreensão de sua própria prática".

A partir dessa constatação, a de que a escrita de si possibilita uma reflexão sobre a própria atuação docente, defendemos a ideia de que, por meio dos diários os professores terão condições de reinventarem, analisar o que está dando certo e tentar readequar determinadas condutas em sala de aula. Para Corsi (2005), a prática de escreverem suas experiências, possibilita ao professor diferentes tipos de reflexões, proporcionando novas formas para desenvolver um trabalho de qualidade no contexto em que atuam.

Ao longo processo investigativo, o estudo de campo procurou buscar por respostas às questões de pesquisas que nortearam o percurso da coleta de dados. Como 
consequência, o planejamento empírico da pesquisa apresentou maior flexibilidade, o que nos possibilitou um (re)desenho dos objetivos a partir do contato com os professores iniciantes colaboradores.

Tal fato ocorre porque segundo Godoy $(1995$, p. 58) "a pesquisa considera o ambiente como fonte direta dos dados e o pesquisador como instrumento chave, possuindo um caráter descritivo, o processo é o foco principal de abordagem e não o resultado ou produto", ou seja, tínhamos inicialmente um projeto de estudo que foi se constituindo melhor a partir do momento em que tomamos contato com a realidade da situação investigada: os desafios dos professores iniciantes em diferentes níveis de ensino.

Nesse contexto, Ludke e André (1986, p.11), esclarecem que “a pesquisa qualitativa tem o ambiente natural como sua fonte direta de dados e o pesquisador como seu principal instrumento." De acordo com a literatura sobre a pesquisa em educação, para que ocorra um estudo qualitativo é necessário o contato direto do pesquisador com o objeto de estudos, o que no caso apresentado nesse artigo deu-se em decorrência do contato da pesquisadora com os professores iniciantes em momentos de coleta dos registros escritos nos diários de campo deles, como também no momento da entrevista, outra técnica de coleta de dados que recorremos com vistas à compreensão das situações enfrentadas no processo de ingresso na carreira docente.

Nesse sentido, podemos dizer que esse estudo teve caráter metodológico que visou relacionar o amplo conjunto de dados, uma vez que utilizamos fontes de informações distintas para a compreensão do objeto de estudos como, por exemplo, o registro escrito com características das narrativas autobiográficas. Além dos diários, também foram realizadas entrevistas semiestruturadas com os professores em início de carreira e a análise de estudos da literatura especializada na temática do professor em início de carreira.

Por fim, após a coleta de dados no primeiro semestre de 2014, fizemos o cruzamento dos dados obtidos por meio da coleta e dos estudos teóricos realizados ao longo dos meses, iniciamos a escrita do artigo científico o qual culminou nos resultados finais da pesquisa. 


\section{CARACTERIZAÇÃO DOS/AS PROFESSORES/AS INICIANTES COLABORADORES DO ESTUDO}

Conforme mencionamos anteriormente, temos como objetivo geral dessa pesquisa investigar os desafios encontrados pelos professores no início da carreira docente, em diferentes níveis de ensino, tendo em vista a formação inicial deles. Para tal precisamos a princípio investigar qual a formação de cada professor, as dificuldades enfrentadas ao ingressarem na carreira docente e conhecer as estratégias adotadas para superá-las no decorrer do ano letivo. A escolha dos professores em primeiro momento foi através do mapeamento por profissionais que estão em início de carreira, considerando que este início seja entre os cinco primeiros anos de docência, após o levantamento entramos em contato como os professores os quais aceitaram e contribuíram voluntariamente com a pesquisa. Desta forma participam quatro professores de diferentes escolas das redes Municipal, Particular e Federal, sendo eles atuantes na Educação Infantil, Ensino Fundamental, Ensino Médio e Ensino Superior, os dados se apresentam no quadro a seguir:

Quadro 01: Caracterização dos professores colaboradores da pesquisa

\begin{tabular}{|l|l|l|l|}
\hline Colaboradores & Idade & Formação & $\begin{array}{l}\text { Tempo de } \\
\text { Atuação }\end{array}$ \\
\hline Professora da Educação Infantil & 21 & Pedagogia/UFMS & 3 (três) anos \\
& anos & & 4 (quatro) \\
& 23 & Pedagogia/UFMS & 5 (cinco) \\
\hline Professora do Ensino Fundamental I & anos & & meses \\
\hline Professora do Ensino Médio & 26 & Ciências & 1 (um) anos e \\
& anos & Sociais/UFMS & 4 (quatro) \\
\hline Professor do Ensino Superior & 24 & Pedagogia e Mestre em & meses \\
\hline
\end{tabular}

Fonte: Elaborado pelos pesquisadores, 2014.

A professora da Educação Infantil optou pelo curso de Pedagogia por não ter condições de fazer outra graduação em municípios distantes de Naviraí/MS. Ela mencionou no momento da entrevista que mesmo iniciando seus estudos não queria ser professora, acreditava que teria muitas dificuldades para lecionar, porém, foi adquirindo o gosto pela docência ao longo da formação inicial. Essa docente ingressou na carreira 
já no segundo ano de sua licenciatura e, atualmente, está em uma sala do jardim I na rede particular de educação local. Como destacado no quadro 01, seu tempo de atuação na carreira docente é de três anos, além da formação em Pedagogia ela iniciou em 2014 um curso de Pós-Graduação Lato-Sensu em Psicopedagogia.

Em relação à professora do Ensino Fundamental I, a opção por fazer Pedagogia decorreu da oportunidade que teve em se vincular a um curso superior, devido não ter condições de fazer faculdade fora do município. De início, teve muitas dificuldades, contudo, hoje "ama o que faz" e no momento não se vê em outra profissão. Essa docente continua buscando novos conhecimentos e atualmente está fazendo PósGraduação Lato-Sensu em Educação Especial e trabalha com uma turma de quarto ano na rede particular de educação.

A professora do Ensino Médio é formada em Ciências Sociais e trabalha em duas escolas estaduais e em uma escola particular como a disciplina de Sociologia e Filosofia, seu tempo de atuação na carreira docente é de cinco meses.

Já o professor do Ensino Superior possui formação em Pedagogia com Mestrado em Educação. Atua em dois cursos de licenciatura há um ano e quatro meses. Para esse professor sua maior realização é ser Pedagogo, ele gosta de estar discutindo a educação porque ela possibilita a pesquisa e sua maior realização é trabalhar com a formação de futuros professores.

Os resultados da coleta de dados das etapas da pesquisa encontram-se descritos nos próximos tópicos de modo a apresentar uma análise reflexiva sobre o ingresso dos professores na carreira docente.

\section{NARRATIVAS DE PROFESSORES INICIANTES: ALGUNS APONTAMENTOS}

Conforme já mencionado anteriormente, a pesquisa teve como objetivo analisar as dificuldades e desafios apresentados pelos professores em início de carreira, os dados aqui apresentados foram obtidos por meio de discussões teóricas numa abordagem autobiográfica, envolvendo professores de diferentes níveis de ensino. Nesse sentido, com base na apresentação dos dados, torna-se possível analisar as escritas dos professores a partir de seus sentimentos da etapa de iniciação à docência, como também de tentar compreender, a partir de suas narrativas, os desencantos e encantos com a profissão.

De acordo com Souza (2007, p. 04): 
As narrativas ganham sentido e potencializam-se como processo de formação e de conhecimento, porque têm na experiência sua base existencial. Desta forma, as narrativas constituem-se como singulares num projeto formativo, porque se assentam na transação entre diversas experiências e aprendizagens individual/coletiva.

A utilização de relatos biográficos vem se tornando uma estratégia que possibilita o estudo das práticas pedagógicas e também um momento oportuno para a reflexão sobre a ação docente. Dessa maneira, conforme ilustrado nos registros escritos dos professores iniciantes colaboradores dessa pesquisa, os dados dos diários mostram marcos constitutivos da carreira docente, as características dos sentimentos revelados pelas narrativas apontam para instabilidade na profissão quando o registro escrito se apresenta ora com mais intensidade, ora com nível menor. Esses pontos apresentam momentos de choque com a realidade (VEENMAN, 1984), pois todos os sentimentos em relação à profissão dependem da trajetória pessoal e intransferível de cada professor iniciante.

Embora tenhamos diferentes níveis de ensino como objeto de estudos na pesquisa, foi possível compreender que os sentimentos do período de indução à carreira se entrecruzam revelando proximidades e uma estreita relação entre conhecimentos teóricos e práticos dos sujeitos. Em relação aos professores da Educação Infantil, do Ensino Médio e do Ensino Superior, podemos perceber que o momento de inserção na docência, foi uma fase "dura" e intensa para ambos, quando nos falam sobre as situações vivenciadas, principalmente no que refere ao sentimento de isolamento e a falta de apoio pedagógico, como podemos verificar em seus registros:

A principal dificuldade que encontrei além da insegurança, foi o sentimento de estar sozinha, minhas colegas de trabalho não me auxiliavam e tive que aprender praticamente sozinha desde o cuidar, até a parte pedagógica (Diário Professora da Educação Infantil, maio/2014).

Entretanto o que muitas vezes dificulta o trabalho é a falta de recursos didáticos dentro da escola e o próprio apoio da direção escolar, isso acaba desmotivando (Diário Professora do Ensino Médio, maio/2014).

Quando cheguei [...] para ser docente, tive vários choques, que, num primeiro momento me deixaram frustrados e quase paralisados. Por pouco não fui embora, abandonando o concurso. De início, senti certa frieza de alguns que seriam os colegas de trabalho e resistência a mim, resistência que senti também por parte de alunos (Diário Professor do Ensino Superior, maio/2014). 
Os dados dessas narrativas apresentam sentimentos decorrentes da socialização profissional desses professores e essa informação é um ponto recorrente nas pesquisas que retratam as dificuldades dos professores iniciantes. Alguns autores apontam que isso ocorre porque o docente principiante encontra-se num momento marcado por conflitos pessoais e profissionais com os quais precisa lidar com desafios e o maior deles refere-se à relação com os demais colegas de trabalho, o que foi declarado pelos professores tanto da Educação Infantil quanto do Ensino Superior.

Freitas (2002) considera que o processo de socialização profissional dos professores iniciantes constitui-se como um momento de aprendizagem de valores, crenças e formas de compreensão de um mundo próprio da cultura ocupacional, ou seja, da dinâmica do trabalho docente para qual o aluno/futuro professor não fora preparado, daí a dificuldade nas relações humanas.

De acordo com a autora, “[...] esse processo pode ser identificado como a aquisição de um ethos profissional, tácito, não necessariamente expresso em palavras, que dá ao agente em socialização o sentido do jogo, isto é, oferece-lhe as condições necessárias para discriminar como deve se portar e atuar" (FREITAS, 2002, p. 156). A questão da socialização do professor novato envolve ainda diferenças e divergências, bem como expectativas profissionais alimentadas a partir de ideário da profissão construído por ele no decorrer de sua formação inicial nos bancos universitários, seja em curso de licenciaturas ou em Pós-Graduação Lato e Stricto Sensu.

Contudo, o processo de socialização não ocorre de forma linear, através de uma incorporação progressiva dos valores do grupo de pertencimento, nem o agente socializado é objeto passivo dos agentes se condições socializadoras. Consideramos, então, que, para a compreensão do processo de socialização profissional, é necessário levar em conta tanto a história do professor iniciante, suas expectativas e projetos quanto às características do grupo profissional a que irá pertencer (FREITAS, 2002, p. 156).

O processo de socialização no espaço escolar vem se demonstrando como uma barreira a ser superada por aqueles que ingressam na carreira docente, mas isso não se apresenta como uma tarefa fácil, haja vista que o corpo docente atuante nesse espaço impõe determinados modos de atuação para aquele que está aprendendo a ensinar. Nesse contexto, no caso do Ensino Superior, essa realidade não é tão diferente da escola, pois no caso pesquisado, o docente iniciante na universidade relata situações de decepção e desencanto com o Magistério: 
Senti que no campus ficaram, de certo modo, decepcionados conosco, professores recém - empossados, porque éramos apenas mestres e não doutores. Todavia, tínhamos passado e derrotado, no processo seletivo, alguns doutores (Diário Professor do Ensino Superior, maio/2014)

A partir dessa escrita, podemos observar que no contexto universitário sobreviver ao início da carreira não é uma tarefa fácil. Com isso, parece-nos que na universidade a luta por espaços e a disputa por "poder" envolve ainda a questão da formação dos profissionais que ali se encontram, ou seja, o nível da titulação, à primeira vista, importa mais do que o caráter da dinâmica da docência, da didática e da relação professor-aluno.

Sabemos que o nível de doutorado é, no campo universitário, uma conquista importante para as universidades e os cursos de formação de professores, contudo, não podemos abandonar o caráter profissional da docência em nome de uma pretensa ideia de que ter doutorado em qualquer área de atuação resolverá as questões práticas dos saberes e conhecimentos profissionais, uma vez que o professor universitário nem sempre ingressa na carreira docente para atuar especificamente com sua linha de pesquisa.

De modo comum, por meio das falas dos professores podemos verificar que suas vivências ao iniciar na carreira docente são muito parecidas, apesar de serem professores de níveis tão distantes. Todos apontam a falta de apoio profissional, pedagógico e o relacionamento como os colegas de trabalho como sendo algumas das principais dificuldades. Mariano (2006) compara esta fase do início da docência com um cenário de teatro ao afirmar:

Achamos que vamos encontrar cada parte do cenário no lugar certo de nossos sonhos, que os atores e atrizes mais experientes vão nos receber de braços abertos e nos ensinar todos os macetes da profissão. Pensamos que a nossa plateia estará sempre sorrindo e atenta à nossa fala (p.19).

Com relação à afirmação do autor, podemos perceber que as características apresentadas acima estão presentes nas narrativas dos professores ao compartilharem suas experiências iniciais com a docência e revelarem suas frustrações/decepções pelo fato de não terem o apoio necessário que precisavam quando ingressaram em seus postos de trabalho. 
Em conformidade com as palavras de Mariano (2006), o professor do Ensino Superior apresenta em sua escrita um trecho que representa bem esta comparação com cenário de teatro.

Eu, que vivera a condição de aluno do ensino superior, agora via de perto os conflitos, as intrigas e as contradições da profissão docente nesse nivel de ensino, o que eu apenas suspeitava, mas não podia ter certeza de como eram os "bastidores" (Diário Professor do Ensino Superior, maio/2014).

A escrita do professor universitário revela pontos do choque de transição entre o estado de estudante para o de professor o que de acordo com Tardif (2007) pode ser denominado também como o choque cultural, ou seja, aquele instante em que o professor novato se vê responsável por questões que antes apenas imaginava como seria. Esse choque cultural ao qual se refere o autor envolve ainda a combinação de etapas formais e informações de aprendizagem da docência pelo professor iniciante que se vale de inúmeras tentativas para lidar com situações adversas, como as "intrigas" relatadas na narrativa acima.

Além disso, um dado frequente em nosso estudo no caso dos professores da Educação Básica, em concordância com outras pesquisas desenvolvidas anteriormente, diz respeito à participação da família nas escolas, principalmente nas privadas, uma vez que os pais dos alunos acabam por "sufocar" o professor iniciante por meio de repressão/cobrança da didática e em decisões tomadas pela escola, fato este recorrente no discurso das professoras de Educação Infantil e dos anos iniciais do Ensino Fundamental.

[...] as duas escolas que trabalhei são particulares, porém nesta que estou hoje os pais influenciam muito nas decisões da escola e isto acaba dificultando nosso trabalho (Diário Professora da Educação Infantil, maio/2014).

Teve alguns imprevistos com alguns pais, pois no colégio particular os pais cobram muito mais de você (Diário Professora do Ensino Fundamental, maio/2014).

Ademais, apesar dessa situação frequente no cotidiano de trabalho dessas profissionais, o desejo de mudança e o sentimento de descobertas acabam por encantálos e fazendo com que não desistam da carreira. Esse fato é comum em todos os níveis de atuação do magistério pesquisados por nós, essa afirmação se respalda nas narrativas abaixo: 
Esses primeiros anos na educação infantil, foram bem dificeis sem apoio, em muitas situações sem saber o que fazer, fiz o meu melhor pela escola e pelos alunos, mas acredito que ao me avaliar posso rever situações que poderiam ser diferentes e hoje posso fazer a diferença (Diário Professora da Educação Infantil, maio/2014).

Em cada plano de aula sempre proponho tipos de avaliações que possibilite que o aluno exponha seus pontos de vistas, participe, e o que encontro muitas vezes durante a aula são propostas diferentes. Cada aula, a cada conteúdo, os próprios alunos me revelam e permitem muitas vezes que minhas aulas preparadas, se diferenciem o que é importante, o conhecimento assíduo de cada sala, que me permite repensar sobre cada aula (Diário Professora do Ensino Médio, maio/2014).

Quero propiciar aos alunos uma formação mais crítica e menos alienante, combatendo essa ideologia do aprender a aprender, do aprender na prática, da Pedagogia como uma ciência a serviço do assistencialismo, dos empresários e de outros interesses escusos que a afastam da escola e da FORMAÇÃO DOCENTE (Diário Professor do Ensino Superior, maio/2014).

A escrita desses professores nos mostra o desejo de mudança na forma de atuação em sala de aula, apresenta que possuem o currículo dos níveis que atuam de forma muito clara em seus entendimentos, como também que têm propriedade para lidar com questões práticas e teóricas da docência nas turmas em que trabalham.

Contudo, esses dados sinalizam que os professores iniciantes colaboradores desse estudo se consideram autônomos ou suficiente para tomar decisões pedagógicas influenciadas por marcas de seu processo de formação ao longo da vida não só profissional como também pessoal. Em outras palavras, eles se reconhecem como profissionais que necessitam ter em suas mãos a direção das ações que pretendem tomar e, talvez, por isso, a fase de ingresso na carreira seja marcada por sentimentos negativos inicialmente, uma vez que a cultura escolar é diferente da cultura de formação e quem está atuando a mais tempo nessa profissão acaba por fixar uma relação hierárquica do posto ocupacional dentro dos níveis de ensino, o que contribui para o sentimento de instabilidade do professor iniciante, conforme verificamos ao desse tópico de análise.

\section{ENTRE O IDEAL E O REAL: ENCANTOS E DESENCANTOS COM A CARREIRA DOCENTE}

A partir da escrita narrativa apresentada pelos docentes em seus diários e observados na sessão de discussão anterior, elaboramos um roteiro de entrevista semiestruturada na tentativa de compreendermos melhor os sentimentos apresentados pelos professores no momento do início da docência. 
Para Veenman (1984) considera que esta fase do primeiro emprego para o professor pode ser muito dramática e até mesmo traumática, essa etapa é chamada pelo autor como "choque com a realidade", instante em que o docente se vê perante situações nunca antes imaginadas por ele, por exemplo, o que reforça o termo utilizado pelo autor.

Dessa forma, verificamos nas falas que na maioria das vezes ao terminar a graduação, os professores possuem grandes expectativas quanto a sua atuação, porém ao chegarem nas escolas percebem que nem tudo é como idealizaram, os modos de organização das instituições de ensino não se apresentam, na maioria das vezes, da forma como descrita em textos estudados durante ao processo de formação.

É nesse momento da realidade que os professores percebem a diferenças dos estudos teóricos que são apresentados nos cursos de formação para o que realmente acontece na prática cotidiana das escolas. Essa afirmação ganha maior respaldo ao destacarmos trechos das falas dos professores iniciantes que explicitam isso:

[...] minhas expectativas nunca foram positivas, eu sempre achei que eu teria bastante dificuldade, porque até então eu não queria ser professora, eu comecei a adquirir esse gosto assim a partir do segundo ano (Professora da Educação Infantil).

[...] eu esperava que seria como o meu passado, as escolas, a maneira de ensinar, seria como, quando eu estava na escola, [...] eu pude ver, que assim, que tudo depende do professor, então depende da maneira que ele planeja, a aula, tudo, e assim, eu esperava ser igual as minhas professoras, só que assim, eu adaptei algumas coisas (Professora do Ensino Fundamental).

[...] o que acontece, a gente sempre sonha com a mudança, a gente chega e quer fazer o melhor, e a gente quer mudar aquilo ali, e ai você entra e vem os primeiros choques, aquelas, aquele contato com os alunos, que você não conhece, as realidades diferentes [...] (Professora do Ensino Médio).

$\dot{E}$ as expectativas é de conseguir de inicio é, algumas transformações que eu acalentava desde a graduação, de poder interferir mais nessa realidade, e nós nos deparamos com algumas estruturas mais rigidas, burocráticas, muitas situações como alunos do ensino superior, por mais que participemos, [...] você não tem uma dimensão exata, das disputas internas, dos conflitos, você não tem tanta dimensão das responsabilidades, dos limites né, então essas questões elas são percebidas realmente agora que eu sou docente, [...] mas minha maior expectativa era de conseguir apresentar autores, que me pareciam importante para um educador conhecer, que me pareciam importante para o trabalho pedagógico, [...] e você acaba tendo, que encontrar vários caminhos, alternativos porque é uma pluralidade de pessoas, de concepções [...] (Professor do Ensino Superior). 
A partir das falas dos professores podemos perceber alguns elementos constitutivos do ideário da prática docente que permeava seus anseios em relação à prática escolar no início de suas carreiras, porém ao ingressarem nas instituições perceberam que muitas de suas concepções teriam que ser revistas, o que gerou a compreensão de que são necessárias algumas mudanças estratégicas para obter melhor desempenho nas atividades de ensino nas turmas em que atuam. Nessa perspectiva, Cunha (2012, p. 143) afirma que:

[...] é possível perceber o professor quando inicia a sua carreira não parte do nada, mas traz à tona sua história de vida, suas experiências, sua socialização em todos os níveis, ou seja, do ambiente familiar, escolar e outros, que foram se acumulando na sua trajetória.

Em conformidade com as palavras da autora, podemos verificar as falas da professora do Ensino Fundamental, onde ela diz que acreditava que iria dar suas aulas como suas professoras faziam no tempo em que ela era estudante da escola dos anos iniciais, ou seja, o ponto de partida para adoção de estratégias didáticas dessa docente tem como pressuposto básico suas experiências enquanto aluna. Já em relação aos demais professores iniciantes participantes dessa experiência de pesquisa, o sentimento de esperança, mudança e a vontade de fazer algo diferente pareciam mais latentes. Contudo, ao se depararem com a burocracia do dia a dia, alguns foram se desmotivando ao longo do tempo.

Outro momento muito importante relatado nas entrevistas diz respeito ao instante em que os professores se depararam pela primeira vez como responsável de uma sala de aula, desde o início do ano letivo. Com isso, na maioria das falas podemos observar a insegurança, o medo, mas também a satisfação de estar ali dando aula, a realização de chegar ao final do ano com a sensação de dever cumprido, esses sentimentos de "sobrevivência" e "descoberta" são melhor ilustrados na fala da professora da Educação Infantil.

Me senti apavorada, não sabia o que fazer, [...] ao mesmo tempo, que eu me senti apavorada, em algumas situações, eu acho que fui bem, [...] te da aquela sensação de insegurança, mas depois quando chega o final do ano eu falei que eu ufa! Eu consegui, mesmo com várias dificuldades (Professora da Educação Infantil).

Corsi (2005) descreve bem essa fase da docência quando destaca que: 
Muitas pesquisas indicam que o início da docência é, frequentemente, um período em que o professor encontra situações inesperadas e às vezes difíceis de serem enfrentadas, mas que também é um período rico na construção de um saber especificamente ligado à prática pedagógica (2005, p.3).

Nesse entendimento, verificamos que ao mesmo tempo em que o professor se depara com situações difíceis e inesperadas, ele consegue, na fase inicial de sua carreira, (re) pensar atitudes, independente das frustações que possa vir a ter em suas primeiras vivências no contexto escolar. Tal situação é evidente no discurso da professora de Educação Infantil ao avaliar os pontos positivos e negativos de sua inserção na docência. Para Huberman (2000), as fases que servem como referência na carreira docente são caracterizadas por mais dois momentos o da "sobrevivência" e o da "descoberta", onde sobreviver está ligado ao choque com a realidade e, consequentemente, com os sentimentos de descobertas.

Huberman (2000, p. 39) afirma ainda que:

[...] ao constatar a complexidade das situações na profissão que envolve o tatear constante, a preocupação consigo próprio, a distância entre os ideais e as realidades cotidianas da sala de aula, a fragmentação do trabalho, a dificuldade em fazer face, simultaneamente, à relação pedagógica e à transmissão de conhecimentos, a oscilação entre relações demasiado íntimas e demasiado distantes, dificuldades com alunos que criam problemas, com material didático inadequado etc.

O autor nos mostra o quanto é "difícil”" ser professor, que trabalhar nas escolas não é uma tarefa fácil, que na teoria estudada durante a formação parece ser tranquilo, mas na prática o educar vai muito além de simplesmente transmitir conteúdos, é no momento de atuação que o novo professor irá se deparar com as dificuldades do sistema educacional.

Essas dificuldades são, frequentemente, evidenciadas na afirmação dos professores iniciantes quando indagamos sobre os modos de superações das dificuldades nos primeiros anos de carreira e revela o quanto um ambiente de trabalho acolhedor e colaborativo pode contribuir para permanência na docência, como também a encontrar respostas para as relações adversas que ocorrem em sala de aula, conforme podemos constatar em suas declarações abaixo:

Ai eu converso bastante, troco bastante ideia com as minhas amigas, [...] é o que as vezes me motiva, assim, troca, conversa, conversa com 
minhas amigas, conversa com outras colegas de trabalho (Professora da Educação Infantil).

[...] eu sempre busco ir atrás dos outros professores, por não ter um coordenador específico para mim, [...] no primeiro ano a minha dificuldade era, a maior também era o medo de não ter pulso firme, de não ter aquele controle, então assim essa era minha maior dificuldade, os conteúdos em si eu buscava os professores ou minha mãe (Professora do Ensino Fundamental).

[...] o desafio maior é dentro da escola, porque eu apareço na escola poucas vezes, [...] então pouco eu tenho contato com os demais que trabalham naquela escola, [...] para superar essas dificuldades que eu venho tendo é a partir da conversa mesmo, de procurar correr atrás de quem sabe mais do que eu, esse seria um dos métodos que eu procuro [...] (Professora do Ensino Médio).

É basicamente assim, é conversando com alguns professores, que vão se tornando mais próximos, mais amigos, às vezes porque experimentaram dificuldades semelhantes, [...] enfrentei muitas dificuldades, então recorri muito a algumas ex. professoras da minha graduação [...] (Professor do Ensino Superior).

Podemos observar que independentemente do nível de ensino, as dificuldades foram muito semelhantes, e que a premissa de que quanto maior o grau de escolaridade a pessoa tiver, mais fácil será sua atuação do professor, não se apresenta como um dado concreto no caso pesquisado, haja vista que cada professor iniciante passa por dificuldades próximas apesar de estarem atuando em níveis tão distintos quando comparamos, por exemplo, a docência na Educação Infantil e no Ensino Superior. Nossa afirmação ganha maior respaldo quando constatado que no relacionamento com colegas de profissão mais experientes, os docentes principiantes do infantil e do superior denunciam certa falta de solidariedade dos professores com tempo maio de serviço e isso, sem dúvidas, é um fator que pode ter dificultado o processo de socialização.

Seguindo essa linha de raciocínio, Cunha (2012) afirma que:

A falta de solidariedade e comportamento de indiferença dos professores mais experientes com os demais pode ser reflexo da exacerbação dos valores neoliberais em que a lógica predominante é o pragmatismo, a competição individual é incentivada e os sistemas de avaliação externa tem como objetivo a ação individual, não a coletiva (p. 145).

É nesse momento que os professores iniciantes se sentem inferiorizados e recorrem às pessoas que de certa forma estão distantes de sua realidade dentro da instituição que estão inseridos. A falta de acolhimento e a indiferença com que principiantes na carreira são recebidos, no caso descrito nessa pesquisa, contribuem 
significativamente para os sentimentos de angústia e medo que fortalecem, de certo modo, o desejo de desistência da profissão. Quanto a esse problema, que é um dado recorrente nas pesquisas sobre o início da docência, Cunha sugere:

[...] que as instituições de ensino devem demandar um professor que estabeleça diálogo com seus pares, que busque planejar coletivamente, que consiga expor e debater as suas condições de ensino, "que discuta a aprendizagem dos alunos e a sua própria formação, que transgrida as fronteiras de sua disciplina, interprete a cultura e reconheça o contexto em que se dá seu ensino e onde sua produção acontece" (CUNHA, 2000 apud CUNHA, 2012, p. 145).

Dessa maneira, corroboramos a sugestão apresentada acima porque acreditamos que quando essa comunicação ocorrer espontaneamente sem que seja uma obrigação, conseguiremos uma melhor recepção dos professores em início da carreira no espaço escolar. Nesse contexto, cabe acrescentar que não só de dificuldades é formado a etapa de iniciação à docência, como podemos verificar, nas falas dos colaboradores desse estudo:

[...] já pensei em desistir várias vezes, mas aí você chega para trabalhar, por mais danadinhos que eles sejam, mas que às vezes eles te fazem chorar, ti cansam, uma palavrinha ali que eles falam, que a mãe chega e fala, oh "hoje fulano chegou em casa falando que aprendeu tal coisa", "fulano não para de falar em você", "fulano te adora", "fulano gosta muito de você", isso pra mim é o que me motiva, é saber que a criança está aprendendo, por mais assim que às vezes é muito, muito, dificil (Professora da Educação Infantil).

[...] me dá prazer, é me dá prazer, eu acho que buscar ensinar é uma coisa que eu aprendi, [...] eu gosto muito de dar aula, [...] eu gosto de resolver os problemas, há eu gosto de buscar as dificuldades de aprendizagem dos meus alunos, é o que eu mais gosto de fazer [...] (Professora do Ensino Fundamental).

O que eu mais gosto, é de estar com os alunos mesmo, o que eu mais gosto é de ... vê eles apresentando trabalho, da prática mesmo, [...] é de estar com eles, de conversar com eles, o que mais me entristece é de saber que eu tenho uma aula por semana, [...] então assim isso que às vezes deixa tão triste, porque o que eu queria era ter mais tempo com meus alunos (Professora do Ensino Médio).

Eu gosto da possibilidade de fazer pesquisa, e ver os resultados dessas pesquisas, de comunicar isso com os alunos, de nos engajarmos em eventos científicos, gosto de observar é, como também nós podemos contribuir com o desenvolvimento dos discentes (Professor do Ensino Superior).

Nesse momento do trabalho, é oportuno relembrar que, apesar das dificuldades e barreiras encontradas pelos professores, é possível observar que o exercício da docência se realiza com amor, gratidão e, acima de tudo, com paciência, principalmente, com 
relação ao contato com os alunos e a busca por novos conhecimentos. Angotti (1998) contribui com essa discussão ao afirmar que independente das dificuldades vividas:

As professoras revelam ter vivenciado um período marcado por sentimentos frágeis, delicados na sua complexidade, tais como o medo, a insegurança, a ansiedade, a apreensão diante do novo, diante do início da atuação profissional. Percebem-se, porém, suas tentativas positivas, para esperança de se prepararem para um bom trabalho (p. 42).

Em suma, frente às questões problematizadas ao longo da escrita desse trabalho de pesquisa, a fala da autora vem ao encontro do sentimento apresentado pelos professores durante a fase das descobertas no campo da docência de forma geral. Mesmo com tantas dificuldades enfrentas pelos professores no início de suas carreiras, como podemos verificar nas falas dos colaboradores, eles ainda encontram muitas razões para continuar, muitas delas são os alunos, pois abandoná-los é ignorar que a educação ainda pode ser mudada, é ignorar o potencial que cada um tem e que somente o professor pode estimular o prazer em estudar em cada um, para tal é preciso reverter a situação dando aos profissionais da educação a devida valorização, tornar a docência mais atrativa tanto para os professores como para os alunos.

\section{CONSIDERAÇÕES FINAIS: O QUE PODEMOS CONCLUIR?}

Durante a escrita desse artigo procuramos relatar as análises dos dados de uma pesquisa desenvolvida em ações no contexto da formação inicial de professores com o foco em retratar o que dizem professores iniciantes de níveis de ensino diferentes em relação aos sentimentos e dificuldades decorrentes do ingresso na profissão. Com base nos dados podemos afirmar que as informações fornecidas pelos colaboradores foram essenciais no processo de escrita do trabalho e que revelam encantos e desencantos com a carreira docente. Nesse sentido, a partir da interlocução entre os autores adotados como referencial teórico e as narrativas dos professores principiantes, procuramos apresentar como ocorre o processo do início da docência, os dilemas e dificuldades enfrentadas no momento da aprendizagem da profissão durante os primeiros anos.

Esse direcionamento da pesquisa levou-nos a compreender melhor a formação inicial dos colaboradores, que ao terminarem suas graduações não ficaram parados, foram em busca de mais aperfeiçoamento profissional com o intuito de melhor atender/ensinar seus alunos, podemos constatar que as dificuldade enfrentadas por eles 
no início da docência não são muito diferentes, como falta de compromisso dos pais, a indisciplina dos alunos, falta de companheirismo de colegas mais experientes, falta de valorização do professor iniciante, falta de apoio pedagógico por parte da gestão das escola, esses são algumas dificuldades apontados por nossos colaboradores e que apesar dos distanciamentos de alguns níveis de ensino, verificamos que os problemas enfrentados são os mesmos ou parecidos, que na maioria dos casos o convívio com os colegas de trabalho é o ponto chave para uma melhor adaptação na instituição, em outros é com a gestão escolar, porém cada professor desenvolveu o seu método de superação das dificuldades, e aprimoramento de seus conhecimento.

Vale ressaltar que mesmo com tantas dificuldades no início da docência, os professores encontram uma esperança para crer em um futuro melhor, ao se depararem com os alunos que alcançam suas metas, faz com que todo o trabalho do professor possa valer a pena. Nos dias atuais ser professor implica ainda desenvolver uma relação de afeto com seus alunos, educando e ensinando para o espaço a ser conquistado por ele e o caminho a ser seguido, momentos esses bem claros nas falas dos professores apresentados em nossa pesquisa, em que a superação das dificuldades que enfrentaram ao ingressarem na docência, acaba ocorrendo pela satisfação do dever cumprido ao término de cada ano letivo.

Contudo, conseguimos verificar no processo de desenvolvimento do estudo, sentimentos de instabilidade em resposta ao modo como esses professores novatos foram "recepcionados" em seus postos de trabalho durante as primeiras vivências, seja na Escola ou na Universidade. Ainda foi possível demonstrarmos que a literatura especializada na área vem contribuindo de forma significativa com o objetivo de detalhar esse momento tão importante da vida do professor, haja vista que é no começo da carreira que esse profissional passa por um período de aprendizagens intensas marcadas por sentimentos de sobrevivências e descobertas, que muitas vezes são responsáveis pelos encantos e desencantos com a docência.

Apesar das dificuldades, que não são poucas, esses professores resistiram e ainda estão firmes em seus locais de trabalho buscando uma melhor forma de se desenvolverem no campo de atuação docente. Cabe destacar também que, a partir da pesquisa, caracterizamos com a colaboração dos professores que o período de inserção profissional pode ser compreendido como uma fase da vida difícil e dolorosa, conforme o título da narrativa escrita pelo professor do Ensino Superior, que demonstra seus 
sentimentos de iniciação à docência: "Ingresso na carreira: Dores, Dilemas e Descobertas" (Diário professor do Ensino Superior, maio/2014).

A respeito do início da docência, estudos vêm mostrando que esta é uma fase tão importante quanto difícil na constituição da carreira de professor. É um momento dotado de características próprias, no qual ocorrem as principais marcas de identidade e do estilo que vai caracterizar a profissional/professora ou o profissional/professor ao longo de sua carreira (LIMA, 2006, p. 09).

Dessa maneira, nossa experiência no trabalho com as narrativas de professores iniciantes demonstrou que essa é uma possibilidade rica e promissora a ser explorada no contexto de auto formação dos participantes desse estudo ao narrarem nos diários reflexivos sentimentos do processo de aprender a ensinar, momento esse que vieram apenas a se confirmar com os relatos apresentados nas entrevistas.

A busca por um referencial teórico consistente sobre a temática investigada nesse estudo juntamente com a pesquisa de campo, proporcionaram uma visão maior de como ocorre o processo de ingresso do professor nas escolas, claro que muitas dúvidas é perguntas ainda existem, porém com menor intensidade agora, e que as relações entre os colegas de profissão devem ser mais ajustadas, os docentes deveriam se unir mais uns com os outros, somente com o apoio dos professores e da coordenação pedagógica é que conseguiremos ter um ensino com mais qualidade.

Por fim, concluímos essa o trabalho de campo defendendo a ideia de que ao narrar um fato o sujeito precisa refletir sobre sua ação para escrever no papel o que pode oportunizar a tomada de consciência de suas ações pedagógicas, bem como a reflexão como possibilidade de desenvolvimento profissional (CIRÍACO; MORELATTI, 2013).

\section{REFERÊNCIAS}

ANGOTTI, M. A pesquisa profissional: os primeiros passos na magistério pré-escolar. Tese de doutorado. CECH/UFSCAR, 1998.

CARTER, K., (1990). Conhecimentos dos professores e aprender a ensinar. Em: HOUSTON, W. R. (org.). Manual de pesquisa sobre formação de professores. Nova York: Macmillan.

CELESTINO, M. R. A formação de professores e a sociedade moderna. Puc. São Paulo SP. 2011. Disponível em: <www.uninove.br/ojs/index. php/dialogia/article/vie761>. Acesso em: 21 nov. 2011. 
CIRÍACO, K. T.; MORELATTI, M. R. M. A reflexão como possibilidade de desenvolvimento profissional no início da docência em Matemática. In: CIRÍACO, K. T.; BEZERRA, G. F. (orgs). Educação Básica, Formação de Professores e Inclusão: práticas e processos educacionais em diferentes cenários. $1^{\mathrm{a}} \mathrm{ed}$. Editora CRV: Curitiba/PR. 2013.

CORSI, A. M. Professores iniciantes: situações difíceis enfrentadas no início da prática docente no ensino fundamental. In: Anais da XXVIII Reunião Anual da ANPEd,2005. Disponível em: http://www.anped.org.br/reunioes/28/inicio.htm. Acesso em: 12, mai. 2014.

CUNHA, M. I. Conta-me agora! As narrativas como alternativas pedagógicas na pesquisa e no ensino. Ver. Fac. Educ., jan/dez 1997. Vol.23, n. 1-2.

CUNHA, M. I. (org.). Qualidade da Graduação: A relação entre ensino, pesquisa e extensão e o desenvolvimento profissional docente. Araraquara, SP: Junqueira\&Marin, 2012. p. 135-183.

FREIRE, P. Pedagogia da Autonomia: saberes necessários à prática educativa. São Paulo: Paz e Terra, 1996.

FREITAS, M. N. de C. Organização escolar e socialização profissional de professores iniciantes. Cadernos de Pesquisa, n. 155, p. 155-172, março/2002.

GATTI, B. A.; BARRETTO, E. S. de S.; ANDRÉ, M. E.D. de A. Políticas docentes no Brasil: um estado da arte. Brasília: UNESCO. 2011, p. 13-85.

GHEDIN, E.; ALMEIDA, M. I.de; LEITE, Y. U. F. Formação de professores: caminhos e descaminhos da prática. Brasília: Líber Livro Editora, 2008.

GODOY, A. S. Introdução a pesquisa qualitativa e suas possibilidades. In, Revista de Administração de Empresa. São Paulo: V.35, n.2, p.57-63, abril 1995.

GUARNIERI, M. R. O início da carreira docente: Pistas para o estudo do trabalho do professor. 2. Ed. Campinas - SP, 2005.

HUBERMAN, M. “O ciclo de vida profissional dos professores”. In: NÓVOA, Antônio (org.). Vidas de professores. $2^{\mathrm{a}}$ ed. Porto, Portugal: Porto Editora. 2000. P. 31-61.

LIMA, E. F. de. (org). Sobrevivências no início da docência. Brasília: Líber Livro Editora, 2006. 104p.

LUDKE, M.; ANDRÉ, M. E. D. A. Pesquisa em educação: Abordagens qualitativas. São Paulo: EPU, 1986.

MARCELO, Carlos. Pesquisa sobre a formação de professores: $O$ conhecimento sobre aprender a ensinar. In: Anais da XX Reunião Anual da ANPEd, Caxambu, setembro/1997. 
MARIANO, A. L. S. O início da docência e o espetáculo da vida na escola: abrem-se as cortinas. IN: LIMA, E. F. de. (org). Sobrevivências no início da docência. Brasília: Líber Livro Editora, 2006. p. 17-26.

MARTINHO, A. M. M. A História da Educação na formação de professores.Máthesis,2000 - crb.ucp.pt. Disponível em: $<$ http://www4.crb.ucp.pt/biblioteca/mathesis/mat9/mathesis9_279.pdf $>$. Acesso em:03, nov.2013.

NONO, M.A. Professores Iniciantes o papel da escola em sua formação. Porto Alegre: Mediação, 2011.

NUNES, C. M. F. Saberes Docentes e Formação de Professores: Um breve panorama da pesquisa brasileira. Educação e Sociedade, ano XXII, nº 74, Abril/2001.

VEENMAN, S. Problemas percebidos de professores iniciantes. Review of Eucational Research, verão, 1984, Vol. 54.nº 2, pp. 143-178.

SOUZA, E. C. História de vida e práticas de formação: escrita de si e cotidiano escolar. Salto para o Futuro/TV Escola/SEED/MEC de 26 a 30 de março de 2007. Disponível em: <http://www.tvbrasil.org.br/fotos/salto/series/165212Historias.pdf $>$. Acesso em: 24, jun. 2014.

TARDIF, M. Saberes docentes e formação profissional. $8^{\mathrm{a}}$ ed. Petrópolis, RJ: Vozes, 2007. 